was used as a diagnostic criterion, but this proportion was reduced to $5 \%$ after adjusting for age.

Three factors may contribute to the observation that systolic pressure is slightly superior to diastolic pressure as a predictor of death from coronary heart disease. Firstly, the larger range between subjects for systolic pressure may more readily identify those at risk for coronary heart disease; secondly, as systolic levels depend partly on arterial compliance ${ }^{19}$ they may provide a better reflection of the degree of underlying arterial disease; and, thirdly, arterial injury may be related more to peak than to mean pressures.

As systolic levels are easier to measure than diastolic levels how would they compare as a guide to the control of high blood pressure? Some information on this might be provided if the data of the completed blood pressure intervention trials were reanalysed so as to relate outcome to systolic and diastolic pressure control considered separately. Meanwhile, future trials of hypertension might do well to use systolic levels alone, or combined with a diastolic index, as their entry criterion. Clinicians tend to concentrate exclusively on the diastolic level when making a diagnosis of hypertension and in instituting and regulating drug treatment; they should be encouraged to pay more attention to systolic pressure.

\section{References}

1 Veterans Administration cooperative study group on antihypertensive agents. A double blind
2 Hypertension detection and follow-up program cooperative group. The hypertension detection and follow-up program. Prev Med 1976;5:207-15.

Multiple risk factor intervention trial research group. Multiple risk factor intervention trial: risk factor changes and mortality results. $\mathcal{f} A M A 1982$;
248:1465-77.

4 Medical Research Council Working Party on mild to moderate hypertension. Randomised controlled trial of treatment for mild hypertension: design and pilot trial. Br Med F 1977; : 1437-40.

5 Report of the Management Committee. The Australian therapeutic trial in mild hypertension. Lancet $1980 ; \mathrm{i}: 1201-7$

Helgeland A. Treatment of mild hypertension: a five year controlled trial. The Oslo study. Am 7 Med 1980;69:725-32.

Isselbacher, KJ, Adams RS, Braunwald E, Petersdorf RG, Wilson JD, eds Harrison's principles of

8 Report of the Joint National Committee on detection, evaluation and treatment of high blood pressure. Arch Intern Med 1980;140:1280-5.

9 Keys A, Taylor HL, Blackburn H, Brozek J, Anderson J T, Simonson E. Mortality and coronary heart disease among men studied for 23 years. Arch Intern Med 1971;128:201-14

10 Kannel WB, Gordon T, Schwarz MJ. Systolic versus diastolic blood pressure and risk of coronary heart disease. Am $\mathcal{F}$ Cardiol $1971 ; 27: 335-45$.

11 Rosenman RH, Sholtz RI, Brand RJ. A Study of comparative blood pressure measures in predicting risk of coronary heart disease. Circulation 1976;54:

12 Rabkin SW, Mathewson AL, Tate RB. Predicting risk of ischaemic heart disease and cerebrovascular disease from systolic and diastolic blood pressures.

13 Miall WE. Systolic or diastolic hypertension-Which matters most ? Clin Exp

Hypertens $[A] 1982 ; 4: 1121-31$.
14 Reid DD, Hamilton PJS, Keen Hett GZ, Jarrett RJ, Rose GA. Cardiorespiratory disease and diabetes among middle aged male civil servants: study of screening and intervention. Lancet $1974 ; \mathrm{i}: 469-73$.

15 Reid DD, Hamilton PJS, McCartney P, Rose GA, Jarrett RJ, Keen H. Smoking and other risk factors for coronary heart disease in British civil servants. Lancet 1976;ii:979-84.

16 Rose GA. Standardization of observers in blood pressure measurement. Lancer 1965 ; $: 673-4$.

17 Rose GA, Holland WW, Crowley EA. A sphygmomanometer for epidemiologists. Lancet $1964 ; \mathrm{i}: 296-300$

18 Breslow NE, Day NE. Statistical methods in cancer research. Vol 1. The analysis of case-control studies. Lyons: International Agency for Research on Cancer, Randall OS. Effect of arterial compliance on systolic blood pressure and cardiac
function. Clin Exp Hypertens $[A] 1982 ; 4: 1045-57$.

\title{
Importance of hypovolaemic shock and endoscopic signs in predicting recurrent haemorrhage from peptic ulceration: a prospective evaluation
}

\author{
P C BORNMAN, N A THEODOROU, R D SHUTTLEWORTH, H P ESSEL, I N MARKS
}

\begin{abstract}
The incidence of rebleeding was studied prospectively in 177 patients with acute gastrointestinal haemorrhage from peptic ulceration with reference to the degree of haemodynamic insult on admission and the presence of endoscopic signs of recent haemorrhage on initial endoscopy.

Rebleeding occurred in two $(2 \%)$ of 114 patients without shock, in seven (18\%) of 38 with tachycardia (pulse rate $>100$ beats $/ \mathrm{min}$, systolic blood pressure $>100 \mathrm{~mm} \mathrm{Hg}$ ), and in $12(48 \%)$ of 25 with shock (systolic blood pressure $<100 \mathrm{~mm}$ Hg). A similar gradient was noted with the presence of endoscopic signs alone. Rebleeding occurred in four (5\%) of 79 patients with no endoscopic signs, in
\end{abstract}

Surgical Gastroenterology Unit, Gastrointestinal Clinic, and Departments of Surgery and Medicine, University of Cape Town, Groote Schuur Hospital, Cape Town, South Africa

P C BORNMAN, MMED(SURG), FRCSED, senior surgeon and senior lecturer in surgery

N A THEODOROU, FRCSED, FRCS, travelling fellow

R D SHUTTLEWORTH, FCSSA, FRCSED, consultant surgeon

H P ESSEL, research assistant

I N MARKS, MSC, FRCPED, head of gastrointestinal clinic

Correspondence to: Dr P C Bornman, gastrointestinal clinic. none of 40 with black spot only, in $11(23 \%)$ of 48 with a clot, and in five $(50 \%)$ of 10 with a visible vessel on endoscopy. When the incidence of rebleeding was assessed in shocked patients, however, it was significantly higher in those with important signs (clot or visible vessel), in $11(79 \%)$ out of 14 patients, than in those with no signs, in one $(9 \%)$ out of $11(p<0.001)$.

These data suggest that the association of shock with important endoscopic signs is a stronger predictor of rebleeding than either shock or important signs alone. More aggressive treatment may be warranted in this small group of patients.

\section{Introduction}

The overall mortality from a single episode of bleeding from peptic ulceration is low. A subsequent haemorrhage, however, during the same admission increases mortality appreciably, particularly in elderly patients. ${ }^{1-5}$ The accurate identification of the few patients likely to rebleed is therefore important.

Recently, endoscopic signs of recent haemorrhage (presence of an old or fresh clot or a visible vessel) within the crater of the ulcer have received attention as useful predictors of further haemorrhage. The incidence of emergency operations for rebleeding in patients with peptic ulceration and any sign of recent haemorrhage has been variably reported between 27 and $53 \%{ }^{6-8}$ 
Except for Griffith's retrospective review, which reported a 100\% incidence of rebleeding in patients in whom the sign was a visible vessel, ${ }^{9}$ most studies report this incidence to be about half. ' The aim of this study was to determine prospectively whether the addition of a simple clinical variable as a second factor-namely, the presence or absence of shock on admission to hospital-could be combined with endoscopic evidence of recent bleeding from a peptic ulcer to allow a more accurate prediction of further haemorrhage.

\section{Subjects and methods}

We studied 177 patients who had been admitted with acute upper gastrointestinal haemorrhage from gastric or duodenal ulcers during the 12 months from August 1981 to July 1982 . The mean (SD) age of these patients was $51 \cdot 2(16.5)$ years, range $23-80$.

All patients underwent full diagnostic endoscopy by an experienced endoscopist within 24 hours of admission. Signs of recent haemorrhage were defined as a visible vessel protruding from the base of the ulcer or the presence of old or fresh clot covering the crater of the ulcer. The presence of black spots within the base of the ulcer was also noted. In the absence of signs the ulcer was accepted as the source of bleeding only when no other lesion was found in the oesophagus, stomach, or duodenum. A record was completed at endoscopy, recording the patients' details and endoscopic findings. The severity of the haemodynamic insult of the episode of bleeding was arbitrarily defined as nil (normal blood pressure and pulse rate), tachycardia only (pulse rate $>100$ beats/min, systolic blood pressure $>100 \mathrm{~mm} \mathrm{Hg}$ ), and shock (systolic blood pressure $<100 \mathrm{~mm} \mathrm{Hg}$ ). We considered rebleeding to have occurred only when subsequent haemorrhage was sufficient to require emergency operation or in a single case when the patient died from uncontrollable haemorrhage without operation during that admission to hospital.

Fisher's test of exact probability was used for statistical analysis of the results. Values of $<0.05$ were regarded as significant.

\section{Results}

In the absence of shock only two $(2 \%)$ out of 114 patients rebled. The incidence of rebleeding increased to seven $(18 \%)$ out of 38 patients who presented with tachycardia alone and $12(48 \%)$ out of 25 with shock.

Table I shows the incidence of rebleeding related to the presence or absence of endoscopic signs alone. Rebleeding occurred more often in patients with important endoscopic signs (clot or visible vessel; $\mathrm{p}<0.001$ ), and within this group occurred more commonly in those with a visible vessel (five $(50 \%)$ out of 10 patients) than those with a clot $(11(23 \%)$ out of 48$)$, but this difference was not significant. Nine of the 11 patients with endoscopic evidence of a clot who came to surgery for rebleeding had a visible vessel at operation; such information was not available on the two remaining patients.

TABLE I-Incidence of rebleeding in patients related to endoscopic signs alone

\begin{tabular}{lcc}
\hline Sign & $\begin{array}{c}\text { Total No of } \\
\text { patients }\end{array}$ & $\begin{array}{c}\text { No (o\%) of patients } \\
\text { rebleeding }\end{array}$ \\
\hline None & 79 & $4(5)$ \\
Black spot & 40 & $11(23)$ \\
Clot & 48 & $5(50)$ \\
Visible vessel & 10 & \\
\hline
\end{tabular}

TABLE II-Incidence of rebleeding in relation to degree of haemodynamic insult and presence or absence of important endoscopic signs (visible vessel or clot)

\begin{tabular}{lcccccc}
\hline & \multicolumn{2}{c}{ Endoscopic sign } & & \multicolumn{2}{c}{$\begin{array}{c}\text { No endoscopic sign, } \\
\text { black spots }\end{array}$} \\
\cline { 2 - 3 } \cline { 6 - 7 } Haemodynamic insult & Rebleed & No rebleed & & Rebleed & No rebleed \\
\hline $\begin{array}{l}\text { Nil }(n=114) \\
\text { Tachycardia }(n=38)\end{array}$ & 1 & 12 & & 2 & 112 \\
Shock $(n=25)$ & $11^{*}$ & 3 & & $1^{*}$ & 10 \\
\hline
\end{tabular}

$* p<0.001$.
Table II shows the effect of the degree of haemodynamic insult of rebleeding in patients with and without important signs. A significantlo higher incidence of rebleeding occurred in patients admitted with shock and important signs (clot or visible vessel; $11(79 \%$ ) out of 14 ) thaf in those admitted with shock and no important signs (one $\left(9^{\circ} \%\right.$ ) out 11) $(\mathrm{p}<0.001)$. Although a higher incidence of rebleeding was note $\bar{f}$. in those with tachycardia and important signs $(29 \%)$ than in thosषo without such signs $(10 \%)$, the difference was not significant. In th group of patients without shock rebleeding occurred in the singlon patient with important signs and in only one of the 113 patients without such signs. Surprisingly, this difference was significant at the $5 \%$ level. Shocked patients with black spots at the base of ulcers fare better than those with important signs $(\mathrm{p}<0.05)$. Rebleeding occurre in 11 of the 14 patients with important signs but did not occur in an of the five patients with black spots.

Other risk factors such as age, sex, and site of ulcer did not have significant influence on the incidence of recurrent bleeding in these subgroups.

\section{Discussion}

The timing of operation for bleeding peptic ulcer has cause controversy for many years with advocates of both early and delayed operation. A case has been made for early operation particularly in elderly patients, who may be most at risk fromb repeated haemorrhage. ${ }^{10}$ Many of these patients, however, arêt also poor operative risks in whom operation should only be carried out if essential. ${ }^{11}$

Although the presence of shock on admission and endoscopic signs may in their own right predict rebleeding, our predictions of rebleeding in $48 \%$ of patients with shock and $50 \%$ with aN visible vessel are not high enough to justify a change from a con $\frac{c}{\tau}$ servative approach to early operation. Individually they identify patients who should be monitored carefully for evidence of further haemorrhage.

We found that the combination of the simple clinical variable of shock on admission and the finding of important signs op recent bleeding (visible vessel or clot) was associated with an incidence of rebleeding of $79 \%$. This suggests that the com bination of these factors indicates a high risk of rebleeding. The results suggest, however, that the presence of black spots within the cavity of the ulcer does not carry the same prognostico weight of rebleeding. The absence of rebleeding in all 40 patients with black spots, including the five shocked patients, suggests that black spots may be a good prognostic feature, even in patients with shock.

More controversial is the importance of endoscopic evidence of a fresh clot, particularly the incidence of an underlying bloodo vessel and the need to establish its presence. The finding of a? visible vessel at operation for rebleeding in at least nine of the $11 \%$ patients with endoscopic evidence of a clot does not necessarily imply that most patients with a clot have an underlying visibleo vessel. Such information was not available for 37 patients whon did not rebleed, and it is not known how many of these had an unidentified visible vessel. Such uncertainty, however, does noto justify the routine washing off of a clot from the crater of an ulcer to allow the base to be examined for a visible vessel, as advocated by some authors. " This procedure may invite an unnecessary rebleed despite allegations to the contrary.

We should emphasise that of the 10 patients with a visiblece vessel on endoscopy in this study, five who rebled had shock $\mathbb{\Phi}$ on admission. Thus not all patients with a visible vessel (with or ${ }^{+}$ without an overlying clot) will rebleed in the absence of shock, $\square$ and this should be considered in an assessment of the efficacy $\frac{\vec{D}}{\mathbb{P}}$ of endoscopic and other medical measures to prevent rebleeding. $\stackrel{\mathbb{P}}{\stackrel{P}{+}}$ Furthermore, variations in the incidence of shock in different $\stackrel{\otimes}{\varrho}$ series may reconcile differences in reported incidences of rebleeding in patients with endoscopic signs.

The therapeutic approach to the high risk group of patients with both shock and severe stigmas remains uncertain. Early operation (or if possible electrocoagulation or photocoagulation in patients at poor operative risks) seems warranted to reduce the morbidity and mortality due to a second haemorrhage, but 
precise guidelines must await the outcome of further controlled studies in this small subgroup of patients.

This study was supported by grants from the South African Medical Research Council and the Staff Research Fund of the University of Cape Town. N A Theodorou received help from the King Edward Fund for London, Simpson Smith travelling fellowship, and Ethicon Foundation. The authors thank their colleagues who helped in the management of patients, and the Chief Medical Superintendent, Groote Schuur Hospital, is thanked for permission to publish this paper.

\section{References}

1 Morgan AG, McAdam WAF, Walmsey GL, et al. Clinical findings, early endoscopy, and multi variate analysis in patients bleeding from the upper gastrointestinal tract. Br Med f 1977; ii :237-40.
2 Van Stiegmann G, Bornman PC, Terblanche J, Marks IN. Bleeding peptic ulcer - with special reference to high-risk groups of patients. Surgical Gastroenterology $1983 ; 2: 245-51$

3 Chang F, Drake JE, Farkes GJ. Massive gastrointestinal hemorrhage in the elderly. Am F Surg 1977; 134:721-3.

4 Hunt PS, Hansky J, Korman MG. Mortality in patients with haematemesis and melaena: a prospective study. Br Med $\mathcal{F} 1979 ; 1: 1238-40$.

5 Hellers $G$, Ihre T. Impact of changes to early diagnosis and surgery in major upper gastrointestinal bleeding. Lancet 1975 ;ii:1250-1.

6 Foster DN, Miloszewski KGA, Losowsky MS. Stigmata of recent haemorrhage in diagnosis and prognosis of upper gastrointestinal bleeding. $\mathrm{Br} \mathrm{Med} \mathcal{F} 1978$;

7 Storey DW, Brown SG, Swain P, et al. Endoscopic prediction of recurrent bleeding in peptic uncers.

of signs of recent haemorrhage at endoscopy.

Med $\mathcal{F}$ Aust $1982 ;$ ii : $35-7$.
9 Griffiths WJ, Neumann DA, Welsh JD. The visible vessel as an indicator of uncontrolled or recurrent gastrointestinal hemorrhage. $N$ Engl f Med 1979 300:1411.

$1 C$ Morris DL, Hawker PC, Brearley S, et al. Optimal timing of operation for bleeding peptic ulcer. Prospective randomised trial. Br Med f 1984;288:1277-80.

11 Vellacott KD, Dronfield MW, Atkinson M, Langman MJS. Comparison of surgical and medical management of bleeding peptic ulcers. Br Med $\mathcal{f} 1982 ; \mathbf{2 8 4}$ 548-50.

(Accepted 29 April 1985)

\section{SHORT REPORTS}

\section{Idiopathic hypopituitarism in the elderly}

The prevalence of pituitary failure in the elderly is unknown. ${ }^{1}$ Equally uncharted are the clinical picture and the aetiology of hypopituitarism when it does occur in this age group. Five patients are presented who showed several common features, raising the possibility that hypopituitarism may be commoner than hitherto suspected.

\section{Case reports}

Case 1-A 90 year old man was admitted with bronchopneumonia. He showed postural hypotension and was clinically hypothyroid. Thyroid function tests showed low serum thyroxine concentrations but thyroid stimulating hormone within the normal range. He was mildly hyponatraemic and had low plasma cortisol concentrations (table). Plain skull films showed a normal pituitary fossa. He responded dramatically to replacement treatment with corticosteroids and thyroxine.

Case 2-A 76 year old woman presented with features of hypothyroidism, disproportionate pallor, and absent body hair. She was found to have subnormal serum thyroxine without a raised thyroid stimulating hormone concentration, mild hyponatraemia, and hypocortisolaemia. Further investigations showed panhypopituitarism and a radiologically normal pituitary fossa (table). Replacement treatment with hydrocortisone and thyroxine produced a pronounced improvement, but she subsequently developed congestive cardiac failure and died from myocardial infarction.

Case 3-An 84 year old woman presented with fainting episodes and severe postural hypotension. She had disproportionate pallor and cool, thin skin. Investigation showed low cortisol, sodium, and thyroxine concentrations with normal thyroid stimulating hormone and adrenals responsive to exogenous adrenocorticotrophic hormone. Further investigations showed anterior pituitary insufficiency and normal skull films. Hydrocortisone and thyroxine improved her clinical state and the postural hypotension resolved, but she died suddenly three months later.

Case 4-An 86 year old congenitally deaf and dumb woman was admitted with diarrhoea. Thyroid function tests disclosed slightly low serum thyroxine concentration but normal thyroid stimulating hormone. She had disproportionate pallor, periorbital oedema, myotonic jerks, thin skin, little pubic hair, and postural hypotension. She was found to have non-insulin dependent diabetes mellitus.

Case 5-This patient first presented in 1976 with a history of blackouts for several years and longstanding pallor. Initial investigations showed low serum thyroxine and plasma sodium concentrations and low urinary sodium excretion. Skull $x$ ray films were normal. Great improvement followed treatment with cortisone acetate and thyroxine. Eight years later he developed a rapidly growing carcinoma of bronchus, confirmed at necropsy.

\section{Comment}

All patients reported on had subnormal serum thyroxine concentrations and, in the four in whom it was measured thyroid stimulating hormone was within the normal range. All had low or low normal plasma sodium concentrations and cortisol concentrations at $0900 \mathrm{~h}$. Adrenal response to Synacthen was deficient when tested, while the use of glucagon in the three women (a more appropriate stress test of secretion of adrenocorticotrophic hormone and growth hormone in this age group than insulin induced hypoglycaemia) showed partial insufficiency of the cortisol response and more profound deficiency of the growth hormone response. Hyperprolactinaemia was not seen. Despite low gonadotrophin secretion at diagnosis all three women had borne children, and two had undergone the menopause aged about 50 . None of the patients was short-one (case 1) was over $180 \mathrm{~cm}$ tall. In no case was aetiology established, but the two pituitary glands examined post mortem showed atrophy. There is little evidence for pituitary atrophy with increasing age. ${ }^{2}$ The data do not permit differentiation between primary pituitary disorder and dysfunction secondary to hypothalamic disease. Vascular insufficiency might have been responsible. ${ }^{3}$ In the context of Sheehan's syndrome, the association of severe pituitary failure and widespread atheroma is well recognised. ${ }^{4}$

Hypopituitarism may occur at all ages. Simple replacement treatment with glucocorticoids and thyroxine may not guarantee prolonged

\begin{tabular}{|c|c|c|c|c|c|c|}
\hline & Case 1 & Case 2 & Case 3 & Case 4 & Case 5 & Normal values \\
\hline $\begin{array}{l}\text { Sex } \\
\text { Age (years) } \\
\text { Thyroxine (nmol/l) } \\
\text { Thyroid stimulating hormone (mU/1) } \\
\text { Peak thyroid stimulating hormone after thyrotrophin releasing hormone (mU/l) } \\
\text { Plasma sodium (mmol/I) } \\
\text { Cortisol at } 0900 \mathrm{~h}(\mathrm{nmol} / \mathrm{l}) \\
\text { Cortisol } 60 \mathrm{minutes} \text { after Synacthen (nmol/l) } \\
\text { Peak cortisol after glucagon (nmol/1) } \\
\text { Basal follicle stimulating hormone, luteinising hormone (U/1) } \\
\text { Peak follicle stimulating hormone, luteinising hormone after gonadotrophin releasing hormone (U/1) } \\
\text { Peak growth hormone after glucagon (mU/l) } \\
\text { Basal prolactin (mU/l) } \\
\text { Peak prolactin after thyrotrophin releasing hormone (mU/l) }\end{array}$ & $\begin{array}{c}M \\
90 \\
20 \\
1 \cdot 0 \\
6 \cdot 0 \\
133 \\
60 \\
203 \\
2 \cdot 4,4 \cdot 6 \\
2 \cdot 4,5 \cdot 1\end{array}$ & $\begin{array}{c}F \\
76 \\
18 \\
3 \cdot 0 \\
3 \cdot 5 \\
133 \\
217\end{array}$ & $\begin{array}{c}419 \\
12,6 \cdot 9 \\
14,12 \\
1 \cdot 1 \\
145 \\
188\end{array}$ & $\begin{array}{c}460 \\
1 \cdot 2,1 \cdot 3 \\
2 \cdot 0,2 \cdot 1 \\
4 \cdot 4 \\
540 \\
1166\end{array}$ & $\begin{array}{l}119 \\
109 \\
213\end{array}$ & $\begin{array}{l}70-140 \\
0-7 \\
\triangle>2 \\
135-145 \\
>180 \\
>500 \\
>550 \\
>28,>29 * \\
>20 \\
<550 \\
>315\end{array}$ \\
\hline
\end{tabular}

